\title{
Banking websites in India: an accessibility evaluation
}

\author{
Arvinder Kaur • Diksha Dani
}

Received: 18 July 2013/Accepted: 8 May 2014/Published online: 24 June 2014

(C) CSI Publications 2014

\begin{abstract}
Accessibility refers to making websites usable for people of all types of abilities and disabilities, regardless of what browsing technology they are using. Since the web is an important resource of information for millions of people at all levels, accessible websites can help people with disabilities too to participate and contribute more actively in society. The objective of this study is to analyze the status of accessibility of banking websites as it allows people with disabilities to be independent and more in control of their own financial requirements. Web Content Accessibility Guidelines (WCAG) are universally accepted guidelines for website accessibility evaluation. The automatic evaluation tool is used to evaluate the website accessibility based on WCAG 1.0 and WCAG 2.0 guidelines. To further assess the reasons for accessibility barriers, complexity score was calculated. The accessibility score of different disability was also computed. The difference between the mean accessibility errors of public and private sector banks in India was also computed. The correlation of accessibility with the popularity and importance of the web sites was also evaluated. It was found that none of the websites that were evaluated were completely accessible to people with disabilities, i.e., there were no web sites that had no violations of web accessibility guidelines. There was no significant difference found in the accessibility of public and private sector banking websites in India. A framework to categorize the websites into fully
\end{abstract}

\footnotetext{
A. Kaur

Guru Gobind Singh Inderprastha University, New Delhi, India

e-mail: arvinderkaurtakkar@yahoo.com

D. Dani $(\bowtie)$

Inderprastha Engineering College, Ghaziabad, India

e-mail: diksha3108@gmail.com
}

accessible, partially accessible and inaccessible was also proposed.

Keywords Accessibility compliance - Web Content Accessibility Guidelines WCAG 1.0 and WCAG 2.0 . Complexity score - Web accessibility · Website importance $\cdot$ Website popularity

$\begin{array}{ll}\text { Abbreviations } \\ \text { WCAG } & \text { Web Content Accessibility Guidelines } \\ \text { W3C } & \text { World Wide Web Consortium } \\ \text { OA } & \text { Overall Accessibility } \\ \text { VI } & \text { Visual Impairment } \\ \text { HI } & \text { Hearing Impairment } \\ \text { CI } & \text { Cognitive Impairment }\end{array}$

\section{Introduction}

The Internet has become an important source of information and communication all over the world. Internet statistics show that there are more than 2 billion internet users in the world. Out of these, 137 million Internet users are in India [1]. Websites and web based user interface for applications are becoming very popular as a means of user interaction and spread of information among differently abled people too. World Health Organization reports that there are approximately 785 million people who live with disabilities in the world [2]. Census 2001 has revealed that over 21 million people in India are suffering from one or the other kind of disability. Out of these disabled in India, 12.6 million are males and 9.3 million are females. Among the five types of disabilities on which data was collected, percentage of visual disability was $(48.5 \%)$, motor 
disability $(27.9 \%)$, cognitive disability $(10.3 \%)$, speech (7.5\%), and hearing disability (5.8\%) [3]. Access to the Internet, to a large extent, decides whether or not these people with different abilities can fully participate and benefit from the internet and participate more actively in the society.

People with disabilities are not able to access much of the important information available on the websites due to their inaccessibility. For example, blind people are not able to see the screen display and use assistive devices like screen readers, which read printed contents, to access the website contents. If the websites do not provide alternatives to visual features like images and videos then the information contained in those graphical features are not conveyed to blind people. Likewise, people with poor vision require screen magnifier to view the contents of the site. Color blind people may find it hard to understand the contents if only the color is used to convey the information. Likewise, information contained in audio material on websites may remain inaccessible to deaf people unless some alternative like text translation like sub-titles are provided for it. Users with physical disabilities like motor movement impairment may face the problem with inaccessible sites like responding to time limited responses on a web page, difficulty in using mouse if there is no support of keyboard alternatives to mouse commands. Users who experience problems with speech face obstacles with websites that require voice-based interaction and support no other input mode. People with cognitive disabilities may face problems accessing the websites that have too many links on a webpage, clear and inconsistent organization of links, complex vocabulary or accent.

Accessible website help in making people with disabilities self reliant by providing facilities like online shopping, bill payments, online trading, online ticketing, online banking, etc. conveniently from their home. The physically impaired users will appreciate and return to websites that they can access easily, especially if the website is transaction based such as banking websites. Therefore, it is important to ensure that people with disabilities, have equal opportunities to benefit from the Web, especially from online public services. Therefore, accessibility of online content has become extremely important.

In this paper, evaluation of banking websites is investigated because internet banking has become an important channel of distribution of financial services all over the world. It is used by people with different abilities to access and use financial services. According to a survey, one in four internet users access banking websites globally [4]. The banking websites have been evaluated from many different perspectives in the past like usability [5-7], functionality [6], navigability [8], internet banking service quality [7, 9-11], etc.
This paper evaluates accessibility of banking websites. Website accessibility provides banks the opportunity to connect to people with special needs which form a significant market segment. The increase in web accessibility broadens the reach of the audience that can use the website. This will enable banks to connect with millions of more people. Transforming business and adapting technology to the needs of people with disabilities promote business and prove to be a significant investment of time, money and resources. In addition to this, it is not only a commercial aspect, but website accessibility allows people with disabilities to access and manage their finances autonomously especially by those with restricted mobility or visual impairment. Accessible websites can make people with disabilities more independent in handling activities like shopping, banking transactions, reading, communicating more easily making a positive impact on their lives. Web accessibility encourages human rights and is ethical and social responsibility too.

In this work, website of Indian banks has been chosen. This is because the internet banking in India is at a nascent stage and is growing very fast. Currently, it is difficult for people with disabilities to use banking services. If a person who has a disability goes to a branch for banking related services, the branch does not have a person or the resources or knowledge on whom to contact to facilitate the interaction [12]. These obstacles mean that a person with a disability always has to depend on to someone who is fully capable to help them. The Reserve Bank of India, which is the central banking authority and regulatory body of the banking industry in India, has advised all banks to make provision to ensure that all banking facilities such as a cheque book facility, ATM facility, net banking facility, locker facility, etc. are offered to person with disabilities without any discrimination. It has also advised banks to take necessary steps to provide ATMs/future ATMs with ramps and to make at least one-third of new ATMs installed as talking ATMs with Braille keypad [13]. But still due to lack of infrastructure and awareness, the people with disabilities face many problems in accessing banking services. With government welfare schemes moving from the cash transfer to transfer into the individual's bank account, it has become all the more important to be able to own and operate a bank account by oneself. Web accessibility can make the difference between frustrating limitations and overwhelming independence.

There are a large number of people in India with differing levels of disability, who would benefit from using banking services through websites. Internet Banking is a tool for people with disabilities to bridge the differences between them and others, and all efforts must be made to ensure that they are not at a disadvantage when it comes to using net banking. 
The rest of the paper is organized as follows: Sect. 2 presents an overview of web accessibility research in the past, Sect. 3 lists out the research questions; Sect. 4 describes the research methodology. Section 5 covers the analysis of the websites and relationship of web accessibility with popularity and web accessibility with the importance of websites. Section 6 describes threats to validity and finally, conclusions are presented in Sect. 7 .

\section{Literature review}

The web accessibility has been the area of research in the past years. This country has gained more importance in the recent years due to the exponential growth in the internet users having various degrees of skill and abilities. Users with disabilities, and the elderly, may experience problems in accessing content on the World Wide Web and depend on assistive technologies and specialized hardware and software.

There are several ways to evaluate accessibility like conformance review, subjective assessment, screening techniques, barrier walk-through, and user testing [14]. In the present study Conformance review method of the evaluation is used. Conformance review is an analytical method based on standards and/or guidelines and includes computer-aided testing with accessibility tools.

W3C's Web Accessibility Initiative developed Web Content Accessibility Guidelines (WCAG 1.0) in 1999 with the aim of providing a single shared standard for web content accessibility that meets needs of individuals, organizations and governments internationally [15]. Later they were succeeded by WCAG 2.0 published in 2008 which are more comprehensive set of guidelines that are compatible with past, present and future technologies [16]. Another development towards web accessibility enhancement was Section 508, which is actually an amendment to the Workforce Rehabilitation Act of 1973 and passed in 1998. It is designed to standardize the accessibility of information technology [17]. Disability Discrimination Act (DDA) of 2004 ensures that websites are accessible to blind and disabled users [18]. Other guidelines in this direction include regulations for creating barrier free technology Barrierefreie Information Technik Verordnung (BITV) in Germany [19]. The website may also be evaluated quantitatively for accessibility using the methodologies like Unified Web Evaluation Methodology (UWEM) [20]. In addition to this, some research projects have addressed the issue of accessibility like eGovMon [21], European Internet Accessibility Observatory (EIAO) [22].

In India the guidelines for web accessibility for government websites GIGW (guidelines for Indian Government websites) have been developed by National Informatics
Centre (NIC) in consultation with International bodies like ISO and W3C. It was formally released in February, 2009 and has been included in the Central Secretariat Manual of Office Procedures (CSMOP) by the Department of Administrative Reforms and Public Grievances, Ministry of Personnel, Public Grievance and Pensions, Government of India. The guidelines address the entire life cycle of a website, web portal/application right from its conceptualization to design, development, maintenance and management [23]. GIGW has three focus domains: Universally accessible (reach), citizen centric (content) and anywhere, anytime, up to date information (management). The majority of the Indian population is not able to read or write in English, while most of the information available on web or electronic media is in English language. Also, most of the screen readers work with English language. Therefore, to reach out to the common man across various sections, an automatic language translator is important. Technology development for Indian languages (TDIL) has initiated to develop Text-toSpeech system in six Indian Languages Hindi, Bengali, Marathi, Malayalam, Tamil and Telugu languages with Braille interface and integrated with other assistive technologies. But there are no general web accessibility laws in India.

Web accessibility principles and guidelines have already become well-known and have been adopted by many countries. Web accessibility evaluations of websites of different domains like education [24-27 etc.], government [28, 29 etc.] have been conducted by various researchers.

Hackett et al. studied the accessibility of higher education websites to study the effect of technological advances and found that Higher education web sites become progressively inaccessible as complexity increases [26]. Kane et al. analyzed the websites of top university websites and found that a large number of websites still have accessibility problems [28]. Hong et al. examined the accessibility of Korean and U.S. government websites using the automated tools and then compared the results obtained by automated tools with that of human evaluation [28]. Other research by Kumar et al. shows that the majority of worldwide government websites are not meeting the needs of their disabled constituents in providing adequate levels of accessibility [30].

To the best of our knowledge, only website accessibility study on Indian websites is a report in which 'The Centre for Internet \& Society' conducted a survey of the accessibility of the government websites in India using both automated and manual evaluations based on WCAG 2.0 recommendations. A total of 7,800 websites listed in the Government of India directory was evaluated for web accessibility and found that only three percent of the websites had no errors and termed accessible [31]. But there is no study on web accessibility of Indian banking 
websites. This study will give the number of violations as well as the relationship between accessibility, complexity, popularity and importance.

\section{Research questions}

The overall objective of the study is to evaluate the accessibility of banking websites for people with disabilities. These are major research objectives:

1. What is the current level of accessibility of banking websites? How many Indian banking websites are accessible to the people with disabilities? To achieve this goal WCAG guidelines have been followed.

2. Which guidelines provided in WCAG 1.0 and WCAG2.0 are violated?

3. What are common types of web accessibility problems?

4. What is the correlation between complexity and accessibility?

5. Is there any difference between accessibility of public and private sector banks?

6. What is the relationship between website accessibility and importance and website accessibility and popularity?

\section{Methodology}

This study evaluates the accessibility of Indian bank web sites. The websites for web accessibility evaluation were selected from the Indian Bank Association website. Indian Bank Association (IBA) formed on 26 September, 1946 as a representative body of management of banking in India operating in India, is an association of Indian banks and financial institutions. It currently represents 173 banking companies operating in India [32].

The objective of this study was to study the accessibility of the Indian bank website so, all the websites listed on the Indian Bank Association (IBA) website under public sector and private sector banks were selected. The data for 48 out of the 49 website listed under public and private sector banks were collected. The web accessibility data of Oriental Bank of Commerce could not be obtained because the tools reported malformed URL error.

To gather data for the study automatic accessibility evaluation TAW was used [33]. TAW is a tool for the analysis of web sites, based on the W3C-Web Content Accessibility Guidelines WCAG 1.0 and WCAG 2.0. It is available both as an online and stand-alone Java application for a variety of platforms. In this study, online version of TAW is used since it evaluates both WCAG 1.0 and WCAG 2.0 guidelines. The application has number of useful features, including: the ability to follow links, enabling developers to spider all of a site's pages up to a defined depth for WCAG 1.0; customizable checklists, to specifically omit certain test or to only test for a subset of WCAG checkpoints; assisted "visual checking", where the tool generates custom versions of the current page with potential problems marked for assessment; dialogs that allow testers to record the results of manual checks (pass/fail/not tested/not applicable); export results to HTML summaries and full EARL reports.

Relationship between web accessibility, the importance and popularity was also investigated. To measure the importance of the website Google page rank score of each website was obtained using an automated tool [34]. Traffic rank data score provided by the Alexa search engine was used to measure the popularity of the website [35].

\section{Web accessibility standards}

To achieve the objectives WCAG 1.0 and WCAG 2.0 guidelines which are the universally accepted standards for web accessibility proposed by W3C were used for the purpose of evaluation of web sites. The tool TAW is used for WCAG 1.0 and WCAG 2.0 evaluation.

In WCAG 1.0 there are certain checkpoints defined for each guideline and each checkpoint has a priority level either 1 or 2 or 3 . Priority 1 checkpoints are those checkpoints which all must be met to achieve a minimum conformance level "A" of accessibility. Similarly, priority 2 checkpoints are those which should be met and if the website meets priority 1 and priority 2 checkpoints, the website achieves "AA" level conformance. If all the checkpoints of WCAG 1.0 are met regardless of the priority, the website has "AAA" level conformance. It takes a URL as input and gives priority 1 errors, priority 2 errors and priority 3 errors as output as per the WCAG 1.0 guidelines. It also reports problems which require manual intervention to assess if correction is required.

WCAG 2.0 is a W3C Recommendation published in December 2008. These guidelines are compatible with both backward and future technologies. WCAG 2.0 consists of four general principles with 12 guidelines that comprise of 61 success criteria which represent testable entity. The principles provide the foundation for web accessibility.

These principles are:

1. Perceivable: Users must be able to perceive the information being presented (it must not be undetectable by all of their senses).

2. Operable: Users must be able to operate the interface (the interface cannot require interaction that a user cannot perform).

3. Understandable: Users must be able to understand the information as well as the operation of the user 
interface (the content or operation cannot be beyond their understanding).

4. Robust: Users must be able to access the content as technologies advance (the content should remain accessible as technologies and user agents evolve).

There are three levels of conformance defined in WCAG 2.0: A (lowest), AA, and AAA (highest).

W3C WAI recommends accessibility evaluation using WCAG 2.0, instead of WCAG 1.0 because it can be applied to current web technologies and to future web technologies irrespective of whether they are W3C technologies or have been developed outside the W3C, e.g. JavaScript, Flash, PDF, etc. WCAG 2.0 also allows more flexibility within the defined parameters and more testable and have clarity and objectivity in the language used. For example, about color contrast criteria WCAG 1.0 says "ensure that foreground and background color combinations provide sufficient contrast when viewed by someone having color deficit" while WCAG 2.0 says "The visual presentation of text and images of text has a contrast ratio of at least 4:5:1 (minimum)".

In this paper both WCAG 1.0 and WCAG 2.0 guidelines have been considered for website evaluation. This is because WCAG 1.0 has been in use for quite some time and well understood and implemented by many tools while WCAG 2.0 is relatively new set of guidelines. Since WCAG 2.0 is the comprehensive version of WCAG 1.0 the websites which conform to WCAG 1.0 may require minor changes in order to conform to WCAG 2.0.

\subsection{Web content compliant analysis for WCAG 1.0}

Banking Industry in India comprises of commercial banks and cooperative banks. The commercial banking structure is categorized into scheduled commercial banks and unscheduled bank. Scheduled commercial banks constitute those banks which have been included in the second Schedule of Reserve Bank of India (RBI) Act, 1934. RBI is a central banking authority and regulatory body of the banking industry. Scheduled commercial banks are further classified into a public sector bank, private sector banks, foreign banks, and regional rural banks.

Currently, India has 80 scheduled commercial banks (SCBs) - 26 public sector banks, 21 private banks and 33 foreign banks [37].

The 48 Indian banking web site's home pages that were analyzed contained a total of 8,592 WCAG 1.0 accessibility guideline violation errors. Out of these, 973 were priority 1 errors, 6,798 were priority 2 errors and 821 were priority 3 errors. The mean number of errors was 179 errors per site with a standard deviation of 232.696 and a minimum of 2 and maximum of 985 errors (Table 1). The
Table 1 Descriptive Statistics of WCAG 1.0 priority errors

\begin{tabular}{lllrlc}
\hline WCAG 1.0 errors & N & Min & Max & Mean & \multicolumn{1}{c}{ SD } \\
\hline Priority 1 & 48 & 0 & 92 & 20.27 & 25.28 \\
Priority 2 & 48 & 1 & 845 & 141.6 & 199.37 \\
Priority 3 & 48 & 0 & 125 & 17.10 & 23.421 \\
Total errors & 48 & 2 & 985 & 179 & 232.69 \\
\hline
\end{tabular}

Table 2 Common WCAG 1.0 errors found in banking websites

\begin{tabular}{|c|c|c|c|c|c|}
\hline $\mathrm{CP}$ & $\mathrm{P}$ & $\mathrm{E}$ & $\mathrm{N}$ & $\%$ & $\mathrm{TE}$ \\
\hline 1.1 & 1 & $\begin{array}{l}\text { Provide a text equivalent for every } \\
\text { non-text element }\end{array}$ & 32 & 66.6 & \\
\hline 3.4 & 2 & $\begin{array}{l}\text { Use relative rather than absolute units } \\
\text { in markup language attribute values } \\
\text { and style sheet property values. }\end{array}$ & 34 & 70.8 & 3,16 \\
\hline 3.5 & 2 & $\begin{array}{l}\text { Use header elements to convey } \\
\text { document structure and use them } \\
\text { according to specification. }\end{array}$ & 45 & 93.7 & \\
\hline 11.2 & 2 & $\begin{array}{l}\text { Avoid deprecated features of W3C } \\
\text { technologies. }\end{array}$ & 37 & 77 & 3,40 \\
\hline 4.3 & 3 & $\begin{array}{l}\text { Identify the primary natural language } \\
\text { of a document. }\end{array}$ & 35 & 79 & \\
\hline 5.5 & 3 & Provide summaries for tables. & 30 & 60.4 & \\
\hline
\end{tabular}

$C P$ checkpoint, $P$ priority, $E$ errors, $N$ number of websites with errors $T E$ total instances of errors

percentage of errors were maximum $79 \%$ of priority 2 errors (Fig. 1b).

Of the 48 home pages that were tested, only 12 conformed to minimum conformance level A i.e. the sites were free of priority 1 errors.

This means that the accessibility of banking websites is at low level indicating that lack of the accessibility policy for web accessibility. This causes lack of providing standard e-banking services for the part of the population with special needs. None of the website conformed to AA and AAA level conformance.

The highest number of errors found in this dataset comprising of all 1,2, 3 priorities was 985 that of union bank of India. The minimum number of total errors of 1, 2, 3 priorities was 2 of Punjab and Sind bank. The mean errors were highest for priority 2 checkpoints.

Most frequently violated WCAG 1.0 checkpoints were "provide alternative text for all non text elements" (66.6\% websites), "Use header elements to convey document structure and use them according to specification" (93.7\% websites), "Use relative sizing and positioning rather than absolute (pixels)" (70.8\% websites), "Provide a summary for tables" (60.4\% websites), "Identify the language of the text" (79\% websites) (Table 2; Fig. 2a).

The limitation in automatic web accessibility is that it cannot differentiate between the ALT tags missing for 


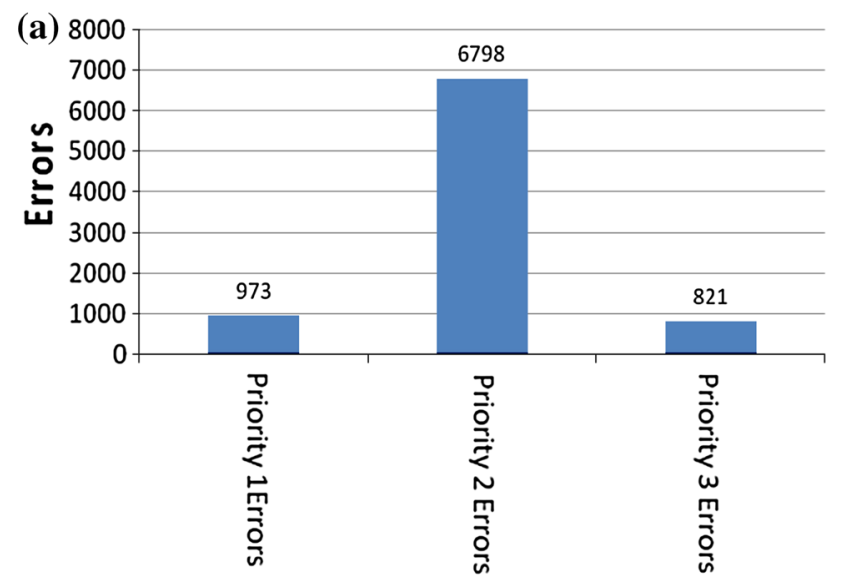

(b)

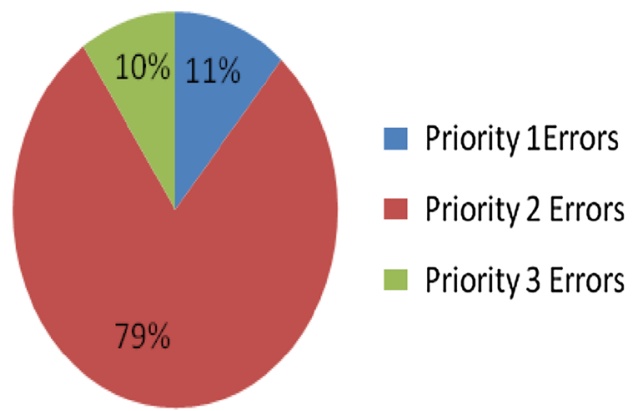

Fig. 1 a Distribution of accessibility errors in the data set of the WCAG 1.0 guidelines. b Percentage distribution of WCAG 1.0 errors

actual images, space images or the images of symbols like question marks, arrow thus mitigating the severity of the errors. Also, meaningless text, inappropriate text or general alternative text for all the images pass the accessibility checkpoint, but offer no support to the people with disabilities.

To summarize the accessibility errors and compute the degree of accessibility, a framework is proposed to categorize the websites into fully accessibility, accessible, partial accessible and inaccessible according to the following algorithm:

Algorithm:

Variables: $\mathrm{P} 1=$ priority 1 errors, $\mathrm{P} 2=$ priority 2 errors, $\mathrm{P} 3=$ priority 3 errors

1. If $(\mathrm{P} 1==0 \& \& \mathrm{P} 2==0 \& \& \mathrm{P} 3==0)$ then "Fully Accessible" Else

2. If $(\mathrm{P} 1==0 \& \& \mathrm{P} 2==0 \& \& \mathrm{p} 3<=10) \quad \|$

$(\mathrm{P} 1==0 \& \& \mathrm{P} 2+\mathrm{P} 3<=10)$ then "Highly Accessible" Else

3. If $(0<\mathrm{P} 1<=10) \& \&(\mathrm{P} 1+\mathrm{P} 2+\mathrm{P} 3<=10)$ then "Low Accessibility" Else

4. "Inaccessible" End.

Based upon the above rules data was analyzed to determine their category of accessibility. It was found that none of the website was fully accessible, nine websites (a) Total Errors

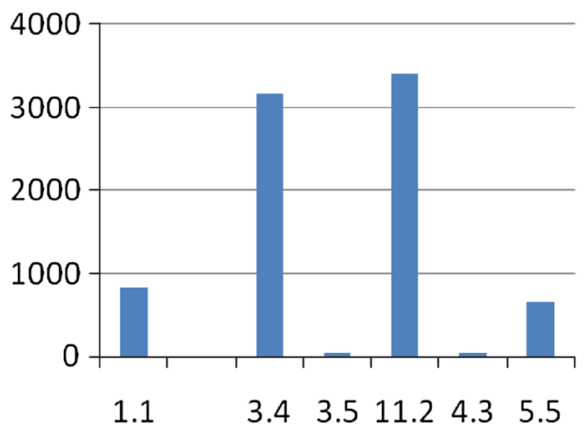

Total Errors

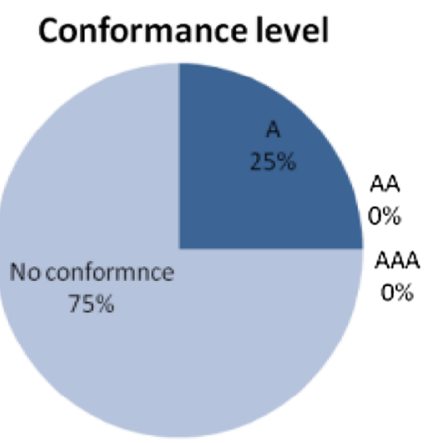

Fig. 2 Distribution according to a Percentage of websites having different checkpoint violations. b Conformance level of website for WCAG 1.0

Degree of accessibility

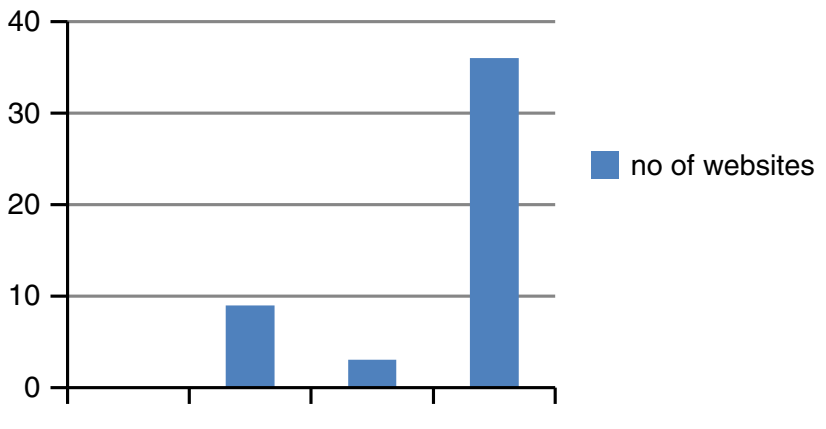

FA HA LA IN

Fig. 3 Number of websites under each category according to framework. $F A$ fully accessible, $H A$ highly accessible, $L A$ low accessibility, $I N$ inaccessible

were highly accessible, three websites came under low accessibility category and thirty-six websites were inaccessible sites. This indicates that web accessibility scenario in Indian banking websites is not very encouraging (Fig. 3). 5.2 Web content compliant analysis for WCAG 2.0

The 48 Indian banking web site's home pages that were analyzed for WCAG 2.0 guideline compliance had a total 

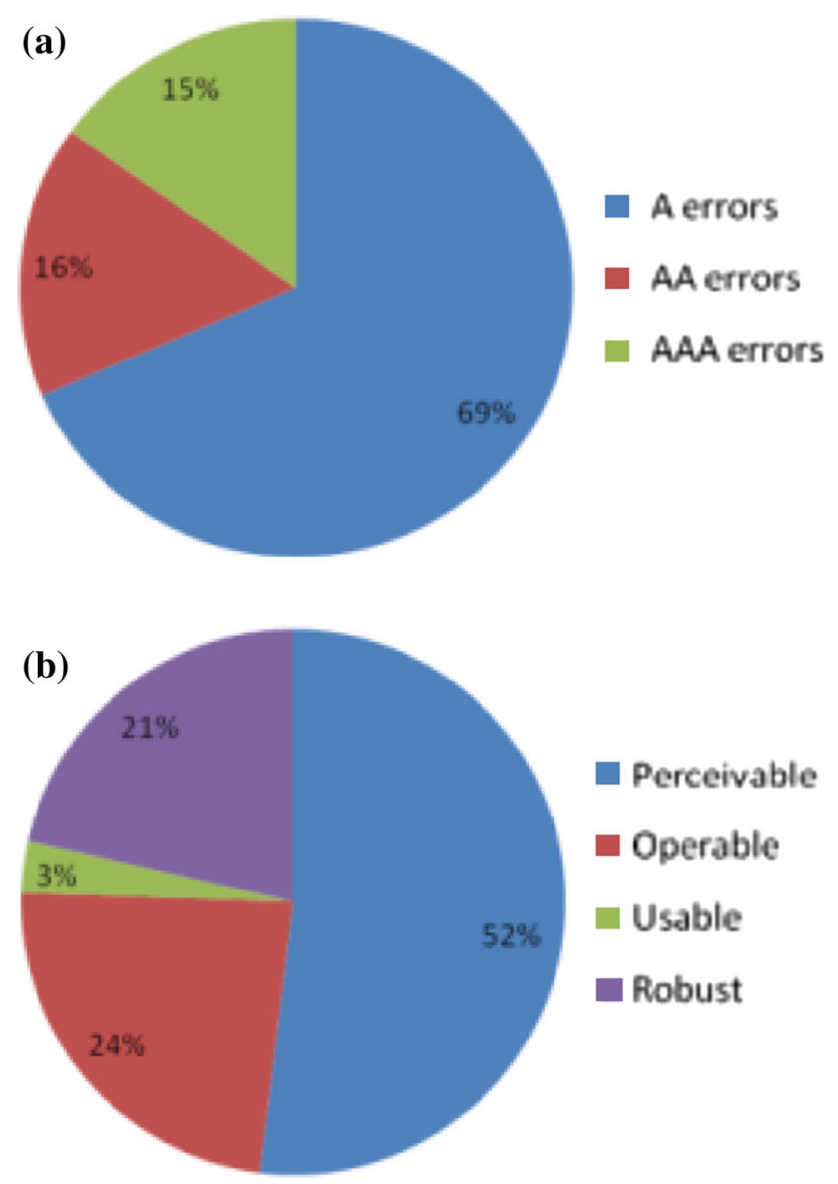

Fig. 4 Percentage distribution according to a Conformance level b Principles for WCAG 2.0 guidelines

of 5,024 errors. Only nine web sites had less than total of 10 errors. The average number of total errors is 104.66 with minimum of 1 error (Indusind bank) and a maximum of 426 errors (Union bank of India).

None of the websites met the minimum accessibility conformance level, i.e. having zero errors for level A conformance and can be said inaccessible. In fact, A level had the maximum total errors in each of the three categories viz. A, AA, AAA. The minimum error in A conformance level was one of Indusind bank and Vijaya bank (Table 3; Fig. 4a).

In Table 3 a grouping of web sites following the WCAG 2.0 principle and error type is presented.

Most errors were related to the first WCAG 2.0 principle perceivable with the average of 54.45. The minimum error was zero of Indusind and Tamilnad Mercantile bank ltd and maximum was 163 of Nainital bank (Table 3; Fig. 4b).

Indian banking websites have not matured enough. Some frequently violated WCAG 2.0 checkpoints of level A conformance were "Non text content" (77\%), "Info and Relationships", i.e. Information, structure and relationship conveyed through presentation can be programmatically
Table 3 Descriptive statistics of WCAG 2.0 checkpoint errors categorized by level and principle

\begin{tabular}{lcllllc}
\hline Error type & Total errors & $\%$ & Min & Max & Mean & SD \\
\hline A & 3,441 & 66 & 1 & 354 & 71.6 & 85.7 \\
AA & 823 & 16 & 0 & 103 & 17.6 & 23.2 \\
AAA & 760 & 15. & 0 & 124 & 15.8 & 23.0 \\
P & 2,614 & 51.8 & 0 & 161 & 54.4 & 51.8 \\
O & 1,186 & 24.5 & 0 & 144 & 24.7 & 26.8 \\
U & 154 & 3 & 0 & 18 & 3.2 & 3.39 \\
R & 1,078 & 20.4 & 0 & 213 & 22.4 & 47.8 \\
\hline$P$
\end{tabular}

$P$ perceivable, $O$ operable, $U$ understandable, $R$ robust

Table 4 Common A level errors for WCAG 2.0 guidelines

\begin{tabular}{|c|c|c|c|}
\hline Errors & Checkpoint & $\begin{array}{l}\text { Number of } \\
\text { websites }\end{array}$ & $\begin{array}{l}\text { Total instance } \\
\text { of errors }\end{array}$ \\
\hline Non text content $(\mathrm{P})$ & 1.1.1 & $37(77 \%)$ & $1,001(19.9 \%)$ \\
\hline $\begin{array}{l}\text { Info and } \\
\text { relationship }(\mathrm{P})\end{array}$ & 1.3 .1 & $45(93.7 \%)$ & $693(13.7 \%)$ \\
\hline $\begin{array}{l}\text { Link purpose (in } \\
\text { context, O) }\end{array}$ & 2.4 .4 & $35(72.9 \%)$ & $378(7.5 \%)$ \\
\hline $\begin{array}{l}\text { Language of a page } \\
\text { (U) }\end{array}$ & 3.1 .1 & $40(83.3 \%)$ & $46(.9 \%)$ \\
\hline Parsing (R) & 4.1.1 & $34(70.8 \%)$ & $1,043(20.7 \%)$ \\
\hline $\begin{array}{l}\text { Name, role, value } \\
\text { (R) }\end{array}$ & 4.1 .2 & $30(62.5 \%)$ & $116(2.3 \%)$ \\
\hline
\end{tabular}

Table 5 Web accessibility scores for different disabilities

\begin{tabular}{lllll}
\hline & OA & VI & HI & CI \\
\hline MA & Vijaya bank & Punjab and Sind & Vijaya bank & Vijaya bank \\
& $76.5 \%$ & bank 77.78 \% & $76.25 \%$ & $82.21 \%$ \\
LA & Karnataka & Bank of India & Bank of & Karnataka \\
& bank & $22.22 \%$ & India & bank \\
& $31.72 \%$ & & $30 \%$ & $42.81 \%$ \\
N1 & 25 & 24 & 27 & 28 \\
N2 & 23 & 24 & 21 & 20 \\
\hline
\end{tabular}

$O A$ overall accessibility, $V I$ visual impairment, $H I$ hearing impairment, $C I$ cognitive impairment

determined or are available in text (93.7\%), "Link Purpose (in context)" (7.5\%), i.e. purpose of each link can be understood from the link text so that users can decide if they want to follow it or not, "Language of a page not identified" (83.3\%), "Parsing" $(70.8 \%)$ i.e. Start and end tags not used according to specifications, and "Name, Role, Value" (62.5\%), i.e. Ensure all elements on a web page have a "Name", "Value" and "Role" assigned to them to enable compatibility with assistive technology, such as screen readers, screen magnifiers, and speech recognition software, used by people with disabilities (Table 4; Fig. 5). 


\section{Total instance of errors}

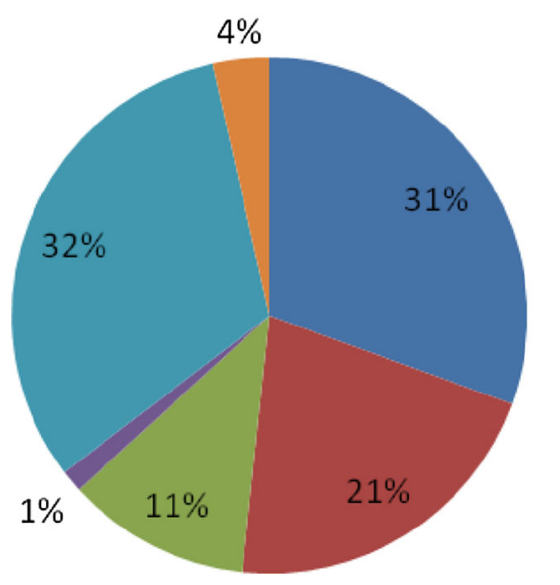

Fig. 5 Total instances of errors of common checkpoints violations for WCAG 2.0

One of the important issues of accessibility in the context of Indian websites is the language of a website page. Language of page criterion is to ensure that content developers provide information on the Web page that user agents need to present text and other linguistic content correctly. The diversity in the script and dialect of a language may pose problems for Visual browsers and assistive technologies to display characters and scripts correctly and screen readers pronounce it correctly. Also, semantic of language may vary according to context in many Indian languages.

To further the accessibility evaluation, accessibility score based on WCAG 2.0 was computed using the web accessibility assessment tool (WAAT) [36]. The tool takes a URL as input and allows user to select between different set of impairments/disabilities, different set of guidelines and personas. The output of the evaluation process is a number of errors and warnings concerning the examined Web application as well as an accessibility score presented in percentage from a scale of $0-100 \%$. An accessibility score of $0 \%$ means no accessibility while $100 \%$ means full accessibility. The tool calculates accessibility score as:

Accessibility score $=100 \times\left\{1-\frac{\sum_{j=1}^{j=N} \sum_{i=1}^{i=n} \frac{\left(B_{i j}\right)\left(W_{i j}\right)}{P \mathrm{ij}}}{\sum_{j=1}^{j=N} \sum_{i=1}^{i=n} W_{i j}}\right\}$

where $\mathrm{N}$ is the total number of pages of the website, $\mathrm{n}$ is the number of success criterion of WCAG 2.0, $B_{i j}$ is the number of violations concerning each success criterion, $\mathrm{P}_{\mathrm{ij}}$ is the number of potential violations, $\mathrm{w}_{\mathrm{ij}}$ is the weight defined for each success criterion of WCAG 2.0 according to priority level. The accessibility score for hearing impairment, vision impairment and cognitive impairment for 46 websites were obtained. The accessibility score for
Table 6 Normality test results

\begin{tabular}{lll}
\hline Parameters & T statistic & Sig. \\
\hline Total errors (wcag 1.0) & .756 & 0 \\
Complexity & .724 & 0 \\
OA & .982 & .684 \\
VI & .958 & .092 \\
HI & .967 & .21 \\
CD & .978 & .536 \\
Total (wcag 2.0) & .837 & 0 \\
\hline
\end{tabular}

Table 7 Mann Whitney test result

\begin{tabular}{lclc}
\hline Test & $\begin{array}{l}\text { Total errors } \\
\text { (WCAG 1.0) }\end{array}$ & Complexity & $\begin{array}{l}\text { Total errors } \\
\text { (WCAG 2.0) }\end{array}$ \\
\hline Mann-Whitney U & 237.000 & 166.5 & 280.000 \\
Wilcoxon W & 513.000 & 442.5 & 556.000 \\
Z & -1.043 & -2.497 & -.155 \\
Asymp. Sig. (2-tailed) & .297 & .013 & .877 \\
\hline
\end{tabular}

UCO bank and State Bank of Mysore could not be obtained. The tool reported "please type valid url/file path. Check the case of automatic redirection to another page".

Vijaya Banks website's accessibility score was found to be greatest for overall accessibility, hearing impairments accessibility and cognitive impairment accessibility score at 76.5, 76.25 and $82.21 \%$, respectively, while Punjab and Sind bank had maximum accessibility score for vision impairment at $77.78 \%$. The Karnataka bank website had a minimum accessibility score for overall accessibility and cognitive impairment accessibility score at 31.72 and $42.81 \%$ respectively, while bank of India had a minimum accessibility score for vision impairment and hearing impairment at 22.22 and $30 \%$ respectively. The highest mean accessibility score was $66.5 \%$ of cognitive disability and the lowest mean accessibility score was $49.7 \%$ of visual impairment (Table 5).

\section{Complexity of websites}

To evaluate the web accessibility further, complexity of websites was examined based on the design components posing different level of barriers to accessibility as proposed by Hackett et al. [26]. The HTML of the web document is parsed and HTML tags, $<$ script $></$ script $>$ tags and $<$ object $></$ object $>$ tags are extracted and complexity score is computed as below:

$\begin{aligned} \text { Complexity }= & \sum(\operatorname{tag} \times 1)+\sum(\text { script } \times 10) \\ & +\sum(\text { object } \times 100)\end{aligned}$ 
Here object being the most complex are given a weight of 100 units, scripts being less complex are given a weight of 10 units and all other HTML tags being least complex are given 1 unit weight as given in [26]. The minimum complexity score was 174 of Karnataka bank while maximum score was found to be 3,766 of Union bank of India.

\section{Comparison between public and private sector banks}

In this section comparison between the websites of Indian private and public sector banks has been done to find out whether there is any difference between the website of public and private sector banks.

To analyze whether there is any significant difference between the accessibility of public and the private sector bank website following hypothesis was formulated:

$\mathrm{H}_{01}$ : There is no significant difference between the public and private sector bank website with respect to total number of violations of checkpoints regarding guidelines WCAG 1.0 .

$\mathrm{H}_{02}$ : There is no significant difference between the public and private sector bank website with respect to total number of violations of checkpoints regarding guidelines WCAG 2.0.

$\mathrm{H}_{03}$ : There is no significant difference between the public and private sector bank website with respect to complexity score.

$\mathrm{H}_{04}$ : There is no significant difference between the public and private sector bank website with respect to accessibility score.

Figure 6 bar chart shows that private banks and public banks do not have any significant difference in the number

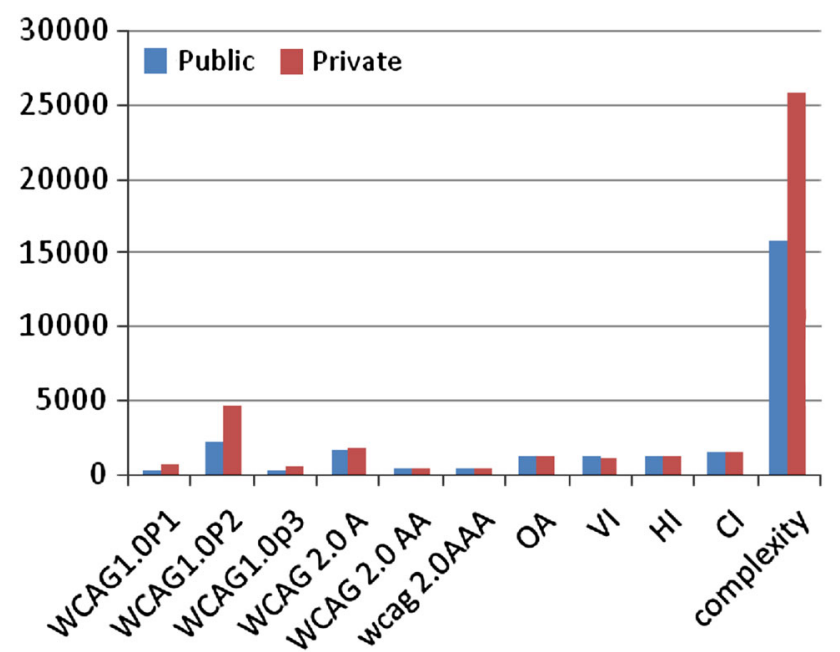

Fig. 6 Distribution of errors and accessibility score between public and private sector banks. $O A$ overall accessibility, $V I$ visual impairment, $H I$ hearing impairment, $C I$ cognitive impairment of errors according to WCAG 1.0 guidelines or WCAG 2.0 guidelines as well as overall accessibility, accessibility of vision impairment, hearing impairment or cognitive impairment though there is some difference between the complexity of both banks.

To further investigate the difference between the public and private sector banks, first the data were analyzed for normality. An assessment of normality of data is done to determine the nature of data and the statistical test that may apply to the data for various analyses.

In the present study, SPSS tool is used to conduct the statistical tests. SPSS uses the Kolmogorov-Smirnov test and the Shapiro-Wilk test for normality testing. The Shapiro-Wilk test is more appropriate for small sample sizes $(<50$ samples), though it can also handle sample sizes as large as 2,000. Since the sample size of this study is $<50$, use of the Shapiro-Wilk test is preferred as the numerical means of assessing normality. If the significance value of the Shapiro-Wilk test is greater the .05 , the data is normal. If it is below .05 , the data significantly deviate from a normal distribution.

The result shows that total errors for WCAG 1.0 guidelines, WCAG 2.0 guidelines and complexity data is not normally distributed since (sig. $<.05)$ while the overall accessibility score, the accessibility score for vision, hearing and cognitive impairment are normally distributed since (sig. $>$.05) (Table 6).

There are various test of significance for normal and non-normal distribution. In this study, Mann-Whitney U test is applied to the non normal distribution and independent sample $t$ test was done to examine the difference between the difference in means of public and private sector banks. Mann-Whitney is a non-parametric test analogous of the unpaired samples $t$ test. The MannWhitney test (also known as the Wilcoxon rank sum test and the Man-Whitney-Wilcoxon test) is performed on ranked data and the hypothesis evaluated is whether or not the median of the difference scores equals zero.

The Mann-Whitney U tests (Table 7) show that there is no significant difference between the public and private sector banking websites with respect to total errors of WCAG 1.0 and WCAG 2.0 (sig. > .05). Since significant value is greater than .05 , hence we fail to reject the null hypothesis $\mathrm{H}_{01}$ and $\mathrm{H}_{02}$. But with respect to complexity score $\left(\right.$ sig. $<.05$ ), we can reject the null hypothesis $\mathrm{H}_{03}$. Hence, we can say that there is a difference between the two groups with respect to complexity score.

The independent sample $t$ test was done for accessibility score of overall accessibility, vision, hearing and cognitive impairment. The independent sample $t$ test (Table 8) of accessibility score shows (sig. $>.05$ ). Hence, the null hypothesis $\mathrm{H}_{04}$ cannot be rejected. It shows that there is no significant difference between the public and private sector 
Table 8 Independent $t$ test result

\begin{tabular}{lrl}
\hline Type & \multicolumn{1}{l}{$\mathrm{t}$} & Sig. (2-tailed) \\
\hline OA & -.338 & .737 \\
VI & .246 & .807 \\
HI & .559 & .579 \\
CI & -.695 & .491 \\
\hline
\end{tabular}

banking in overall accessibility, Vision impairment, hearing impairment and cognitive impairment accessibility score. The accessible websites do not compromise on site's visual design or interactivity.

\section{Relationship of accessibility with other parameters}

In this section relationship of accessibility with other parameters considered in this study like website importance, website popularity and complexity score are investigated.

Page rank is a link analysis web metric that measures the importance of a web page. Google page rank is used to compute the importance of the web page. According to Google, web pages with a higher Page Rank are more likely to appear at the top of Google search results. Page Rank may be considered as one of the approaches to assess the quality of a website on the assumption that good sites get more links, since page rank depends upon the number and quality of backlinks coming to the webpage and their visibility. More the backlinks of a particular webpage higher will be the page rank of a webpage. It also depends upon the quality of backlinks. Page rank is measured on a scale of $0-10,10$ being most popular pages.

Assuming the traffic to be an indicator of accessibility, traffic ranking data of each website that is provided by Alexa were used as a measure of popularity of the websites. Alexa measures the site's value on the basis of two things:

(1) Number of visitors to the site.
(2) How many pages they visit.

The Alexa traffic rank is calculated after collecting aggregated data from Alexa toolbar users over a period of 3 months.

To analyze the relationship between the accessibility and popularity and importance, following hypothesis was formulated:

$\mathrm{H}_{01}$ : There is no significant relationship between accessibility and website importance.

$\mathrm{H}_{02}$ : There is no significant relationship between accessibility and website popularity.

$\mathrm{H}_{03}$ : There is no significant relationship between accessibility and complexity score.

Spearman correlation was used to measure the degree of correlation between web accessibility and different metrics using the SPSS software package.

Spearman rank-order correlations were conducted in order to determine if there was any relationship between web accessibility and importance, web accessibility and popularity. The SPSS output a cross tabulation table that includes a value for Spearman's Rho and a 2-tailed significance value.

(1) If the value of Sig. reported is equal to or less than .05 (at the $95 \%$ level of confidence) or .01 (at the $99 \%$ level of confidence), the correlation is statistically significant and the null hypothesis is rejected (2) If the value of Sig. reported is greater than .05 (at the $95 \%$ level of confidence) or .01 (at the $99 \%$ level of confidence), the correlation is not statistically significant and the null hypothesis must be accepted

In the present case a two-tailed test at significance level .01 indicated that there seem to be no significant relationship between accessibility and any of the parameters under study, i.e. complexity, importance and popularity since significant value of WCAG 1.0 and WCAG 2.0 with complexity, importance and popularity is greater than .01 . So the hypothesis $\mathrm{H}_{\# 1}, \mathrm{H}_{\# 2}, \mathrm{H}_{\# 3}$ cannot be rejected.
Table 9 Spearman correlation between accessibility, complexity, importance and popularity

Comp complexity, Imp importance, Pop popularity

** Correlation is significant at the .01 level (2-tailed)

Listwise $\mathrm{N}=48$

\begin{tabular}{lllllll}
\hline Parameters & & WCAG 1.0 & WCAG 2.0 & cmplexity & Imp & Pop \\
\hline \multirow{2}{*}{ WCAG 1.0 } & Correlation Coefficient & 1.000 & $.703^{* *}$ & .090 & .026 & .051 \\
& Sig. (2-tailed) & - & .000 & .545 & .859 & .732 \\
\multirow{2}{*}{ WCAG 2.0 } & Correlation Coefficient & $.703^{* *}$ & 1.000 & .233 & .104 & -.051 \\
& Sig. (2-tailed) & .000 & - & .112 & .480 & .731 \\
cmplexity & Correlation Coefficient & .090 & .233 & 1.000 & $.433^{* *}$ & $-.505^{* *}$ \\
& Sig. (2-tailed) & .545 & .112 & - & .002 & .000 \\
Imp & Correlation Coefficient & .026 & .104 & $.433^{* *}$ & 1.000 & $-.737^{* *}$ \\
& Sig. (2-tailed) & .859 & .480 & .002 & - & .000 \\
Pop & Correlation Coefficient & .051 & -.051 & $-.505^{* *}$ & $-.737^{* *}$ & 1.000 \\
& Sig. (2-tailed) & .732 & .731 & .000 & .000 & - \\
\hline
\end{tabular}


However, there was a significant relationship between complexity and importance, complexity and popularity as sig $=.000$ is less than .01 . There is a positive correlation between complexity and popularity (.433) and negative significant correlation between complexity and popularity $(-.505)$ indicating the complex object design make the website less popular. However, there seems to be no correlation between the total accessibility errors of WCAG 1.0 and WCAG 2.0 and importance or popularity or complexity (Table 9).

\section{Threats to validity}

Though measurement of accessibility using an automatic website accessibility tool is easy and convenient, but the automatic tools cannot differentiate between the severity of the errors of the same checkpoint. Also, not all the guidelines are checked. Some of the guidelines require human judgment. It should also be taken into consideration that the web pages analyzed in the study may be changed or updated. Thus, the results in this study reflect the status of the pages on the dates when the study was carried out, i.e. Jan 2013.

\section{Conclusion}

The study provides an insight into the commonly violated checkpoints of the WCAG guidelines. Results showed that many Indian banking continues to have accessibility problems. Full compliance with existing accessibility guidelines WCAG 1.0 and WCAG 2.0 remains to be low. The result showed only 12 websites out of 48 websites, i.e. $25 \%$ conform to minimum conformance level with respect to WCAG 1.0 and none of the websites conform to minimum conformance level with respect to WCAG 2.0. The results of the evaluation indicate that the situation of website accessibility of Indian banking websites is not very satisfactory in terms of number of errors reported by the automatic tools. The tool reported total of 8,592 instances of violation with mean of 179 errors for WCAG 1.0 and 5,024 instances with mean of 104.66 errors for WCAG 2.0. This shows that Indian banks fail to provide accessible and barrier free environment in online services and websites are difficult to be accessed by disabled users.

The result also shows that there is no difference between public and private sector bank website with respect to WCAG 1.0, WCAG 2.0 and accessibility score but there is a difference between them in complexity score. A twotailed test of significance indicated the there was no significant relationship of accessibility with complexity, importance and popularity. It also shows a significant positive relationship between complexity and importance (.433) while there is negative significant correlation between complexity and popularity $(-.505)$ indicating the complex object design make the website less popular.

But it should also be taken into consideration that these automatic tools do not differentiate between the severity of errors as a result of which we may not get the true picture of the accessibility status. Another issue that should be considered while evaluating Indian websites is that the website may have content in regional language. There is a need to develop a multi linguistics model in Indian context. But web accessibility does not depend entirely on technical and WAI standards, but is considerably affected by several other factors like device characteristics, situational circumstances resulting due to factors like usage context, surrounding light and sound or mental state of the individual.

There is also a need for awareness among the developers and designers that websites complying with accessibility standards are easier to develop, update and maintain. The designers as well as government have started looking into this aspect and it is hoped that web accessibility will improve further as we move to accessibility for all.

\section{References}

1. Internet world statistics (2013) http://www.internetworldstats. com/stats. Accessed 2013

2. World report on disability. Available at : http://www.who.int/ disabilities/world_report/2011/report/en/. Accessed July 2012

3. Census (2001) http://censusindia.gov.in/Census_And_You/ disabled_population.aspx

4. comScoredatamine post (2012) http://www.comscoredatamine.com/ 2012/06/1-in-4-internet-users-access-banking-sites-globally/. Accessed 2012

5. Chin-Shan W, Cheng F, Lin H (2004) Web site usability evaluation of internet banking in Taiwan. J Internet Bank Commer, $9(1)$

6. Eduardo D, Morena PR, Tomi A (2005) Internet banking in Brazil: evaluation of functionality, reliability and usability. Electron J Inf Sys Eval 8(1):41-50

7. Wenham D, Zaphiris P (2003) User interface evaluation methods for internet banking web sites: a review, evaluation and case study. In Jacko J, Stephanidis C (eds), Human-computer interaction, theory and practice, $\mathrm{p}$ 721-725

8. Bonsón-Ponte E, Escobar-Rodríguez T, Flores-Muñoz F (2008) Navigation quality as a key value for the webpage of a financial entity. Online Inf Rev 32(5):623-634

9. Achour H, Bensedrine N (2005) An evaluation of internet banking and online brokerage in Tunisia: In: Proceedings of the 1st International Conference on EBusiness and E-learning (EBEL), Amman, Jordan, p 147-158

10. Khan MS, Mahapatra SS (2009) Service quality evaluation in internet banking: an empirical study in India. Int J Indian Cult Bus Manag 2(1):30-46

11. Vijayan P, Shanmugam B(2003) Service quality evaluation of internet banking in Malaysia. J Internet Bank Commer 8(1) 
12. Maheshwary V (2012) Banking and accessibility in India: a study on banking accessibility in India, The center for Internet and Society

13. RBI circular. Banking facilities to visually challenged/persons with disabilities Circular RPCD.CO.RRB.BC.No.13/03.05.33/ 2008-09 dated July 23, 2008. Available at: http://rbidocs.rbi.org. in/rdocs/notification/PDFs/CE249BF121012.pdf. Accessed 2013

14. Brajnik G (2008) Beyond conformance: the role of accessibility evaluation methods. In: Proceedings of WISE 2008 workshop, LNCS 5176, p. 63-80

15. W3C: Web Content Accessibility Guidelines [online]. Recommendation, W3C. http://www.w3.org/TR/WCAG1.0/.(1999)

16. W3C (2008) Overview of WCAG 2.0 Documents, [online] Web accessibility initiative. http://www.w3.org/WAI/intro/wcag20. $\mathrm{php} /$

17. Section 508 of the Rehabilitation Act of 1973 . Web accessibility guidelines section 508. http://www.section508.gov. (1998, amended)

18. Blue L (2001) Web site design and the Disability Discrimination Act 1995. Comput Law 12(5):16-20

19. Buhler C, Wallbruch R (2005) E-accessibility in Germany: acts and ordinances, outcome of benchmarking and activities[online]. Policies and legislations in favor of e-accessibility in Europe Conference, Paris, France. http://braillenet.org/colloques/poli cies/documents/WallBruch.rtf

20. UWEM (2005) Web accessibility benchmarking cluster: D-WAB2 unified web evaluation methodology (UWEM 0.5), 2005. Available at: http://www.wabcluster.org/uwem05/

21. eGovMon, eGovMon-eGovernment monitor (2008) http://www. egovmon.no/en/. Accessed in 2013

22. EIAO (2008) Main-European internet accessibility observatory. http://www.eiao.net/. Accessed in 2013

23. GIGW Guide for Indian government websites.(2009) http:// egovstandards.gov.in/guidelines/guidelines-for-indian-governmentweb-sites

24. Clyde LA (2004) School library web sites: 1996-2002. Electron Libr 22:158-167
25. Comeaux D, Schmetzke A (2007) Web accessibility trends in university libraries and library schools. Libr $\mathrm{Hi}$ Tech 25(4):457-477

26. Hackett S, Parmanto B (2005) A longitudinal evaluation of accessibility: higher education web sites. Internet Res 15(3):281-294

27. Kane S, Shulman J, Ladner R, Shockely T (2007) A web accessibility report card for top international university web sites. In: Proceedings of W4A2007, ACM, pp 148-156

28. Hong S, Katerattanakul P, Lee D (2008) Evaluating government website accessibility: software tool vs. human experts. Manag Res News 31(1):27-40

29. Hyun J, Moon J, Hong K (2008) Longitudinal study on web accessibility compliance of government websites in Korea. In: APCHI '08 Proceedings of the 8th Asia-Pacific conference on Computer-Human Interaction, p 396-404

30. Kuzma J, Yen D, Klaus O (2009) Global e-government web accessibility: an empirical examination of EU, Asian and African sites. In: Second international conference on information and communication technologies and accessibility, Hammamet, Tunisia, 7-9 May 2009

31. Narasimhan N. (2013) Accessibility of government websites in India: a report. Available at: http://cis-india.org/accessibility/ accessibility-of-govt-websites.pdf. Accessed 2013

32. IBA. Indian Bank Association website (2013) http://www.iba.org. in. Accessed 2013

33. TAW (2012) Accessibility evaluation tool. http://www.tawdis. net/ingles.html

34. Google page rank calculation tool www.prchecker.info/check page_rank.php

35. Alexa traffic rank calculation tool. www.alexa.com

36. WAAT. Web accessibility assessment tool. Available at: www. accessible-eu.org/index.php/waat.html

37. Joshi A R (2011) Director banking studies and Risk Modelling Division Department of Statistics and Information Management Reserve Bank of India. A profile of banks: 2010-11. Available at http://rbidocs.rbi.org.in/rdocs/Publications. Accessed 02 Sep 2011 